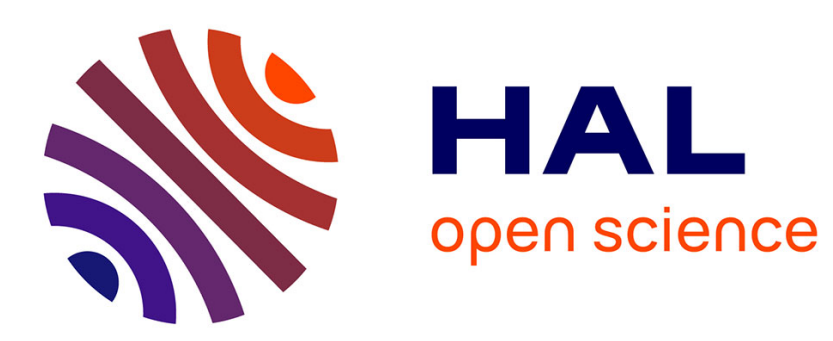

\title{
Customer empowerment in the face of perceived Incompetence: Effect on preference for anthropomorphized brands
}

\author{
Jamel Khenfer, Steven Shepherd, Olivier Trendel
}

\section{- To cite this version:}

Jamel Khenfer, Steven Shepherd, Olivier Trendel. Customer empowerment in the face of perceived Incompetence: Effect on preference for anthropomorphized brands. Journal of Business Research, 2020. hal-03189338

\section{HAL Id: hal-03189338 \\ https://hal.science/hal-03189338}

Submitted on 3 Apr 2021

HAL is a multi-disciplinary open access archive for the deposit and dissemination of scientific research documents, whether they are published or not. The documents may come from teaching and research institutions in France or abroad, or from public or private research centers.
L'archive ouverte pluridisciplinaire HAL, est destinée au dépôt et à la diffusion de documents scientifiques de niveau recherche, publiés ou non, émanant des établissements d'enseignement et de recherche français ou étrangers, des laboratoires publics ou privés. 


\section{Journal of Business Research \\ Customer Empowerment in the Face of Perceived Incompetence: Effect on Preference for Anthropomorphized Brands \\ --Manuscript Draft--}

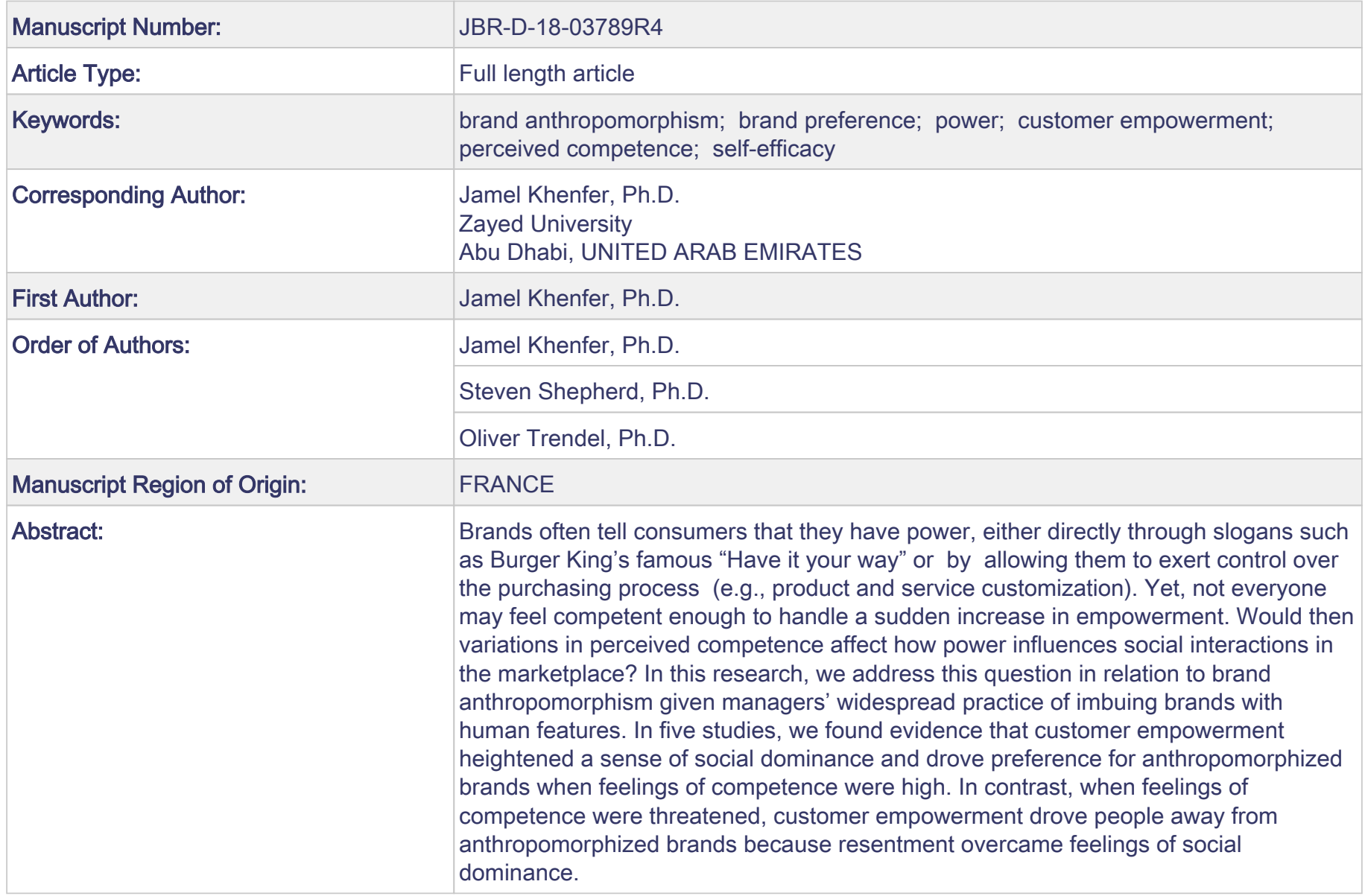


June 4, 2020

Dr. Naveen Donthu, Dr. Anders Gustafsson

Editors-in-Chief

Journal of Business Research

Dear Dr. Donthu, dear Dr. Gustafsson,

My coauthors and I were thrilled to receive the final decision letter on our manuscript referenced JBR-D-18-03789R3, under the following title: "Customer Empowerment in the Face of Perceived Incompetence: Effect on Preference for Anthropomorphized Brands."

We have made sure to format the paper according to the journal's guidelines. All authors have read and followed the journal's instructions for authors, and all authors have approved submission of this paper. This manuscript has not been published, is currently not under consideration elsewhere, and does not contain data that are currently submitted or published elsewhere. The authors have control over the data and agree to allow the journal to review the data if requested. The American Psychological Association's (APA) Ethical Principles of Psychologists and Code of Conduct guided our research.

Sincerely, 
Running head: Brand preference in context of empowerment

Customer Empowerment in the Face of Perceived Incompetence: Effect on Preference for Anthropomorphized Brands

Jamel Khenfer $^{\mathrm{a}}$, Steven Shepherd ${ }^{\mathrm{b}}$, Olivier Trendel ${ }^{\mathrm{c}}$

${ }^{a}$ Zayed University, College of Business

Address: P.O. Box 144534, Abu Dhabi, United Arab Emirates

Email: jamel.khenfer@zu.ac.ae

Office phone: +97125993484

Corresponding author

${ }^{\mathrm{b}}$ Oklahoma State University, Spears School of Business

Address: Stillwater, OK 74078, United States

Email: steven.shepherd@okstate.edu

${ }^{\mathrm{c}}$ Grenoble Ecole de Management

Address: 12 rue Pierre Sémard, F-38000 Grenoble, France

Email: olivier.trendel@grenoble-em.com 


\begin{abstract}
Brands often tell consumers that they have power, either directly through slogans such as Burger King's famous "Have it your way" or by allowing them to exert control over the purchasing process (e.g., product and service customization). Yet, not everyone may feel competent enough to handle a sudden increase in empowerment. Would then variations in perceived competence affect how power influences social interactions in the marketplace? In this research, we address this question in relation to brand anthropomorphism given managers' widespread practice of imbuing brands with human features. In five studies, we found evidence that customer empowerment heightened a sense of social dominance and drove preference for anthropomorphized brands when feelings of competence were high. In contrast, when feelings of competence were threatened, customer empowerment drove people away from anthropomorphized brands because resentment overcame feelings of social dominance.

Word count: 138
\end{abstract}

Keywords: brand anthropomorphism; brand preference; power; customer empowerment; perceived competence 


\section{Customer Empowerment in the Face of Perceived Incompetence: Effect on Preference for Anthropomorphized Brands}

\section{Introduction}

Managers often anthropomorphize brands; that is, they imbue brands with physical characteristics and behaviors that resemble those of people. This may include visual cues such as logos and displays of inanimate objects in human postures (e.g., the M\&M's mascots, the Pixar lamp), verbal tactics such as names (e.g., Mr. Clean), and rhetoric designed to attribute human-like capacities to inanimate objects (e.g., "Like a good neighbor, State Farm is there") (MacInnis \& Folkes, 2017). In general, imbuing brands with human features generates more favorable consumer attitudes (Aggarwal \& McGill, 2012).

Previous research suggests that empowered consumers respond favorably to brands bearing human-like features because such brands can entice consumers to feel socially dominant, even if it involves inanimate objects (Kim \& Kramer, 2015; Kim \& McGill, 2011; 2018; Maeng \& Aggarwal, 2018). In this research, we suggest that this is not always true. Consider the following example. Banks increasingly empower their customers by having them conduct operations on their own to reduce physical service encounters (e.g., managing their financial portfolio online). Yet, some customers may feel incompetent, perhaps, because of difficulties in managing their money (e.g., the $30 \%$ of Americans with a credit score lower than 650, Bloomberg, 2017), or because they are disconnected from the digital world despite its key role in customer empowerment strategies (e.g., the $40 \%$ of Americans above 65 who do not use the Internet, Pew, 2014). Would such individuals respond favorably to anthropomorphic virtual assistants such as Bank of America's Erica? Or would they be reluctant to share their lack of competence? 
In the present research, we suggest that empowered consumers respond favorably to anthropomorphic brands only when their feelings of competence-i.e., their perceived ability to skillfully interact with and alter the environment (Fast \& Chen, 2009)—are high. We argue that the feeling of dominance experienced over a (non-human) entity projecting intelligence and personality may conflict with the negativity associated with heightened feelings of incompetence in the presence of others. Evidence shows that when power holders feel unable to meet the demands of the leadership situation they are in, their relationship with subordinates becomes strained because they experience insecurity and diminished self-worth (Fast, Burris, \& Bartel, 2014; Fast \& Chen, 2009). Therefore, we propose that when a given situation heightens feelings of incompetence, empowered consumers respond unfavorably to anthropomorphized brands because they experience resentment. We argue that the negativity their forceful presence entails overshadow the experience of social dominance that was promised through empowerment. We report on five studies that provide support for the moderating role of perceived competence both as a trait and a state.

\section{Theoretical background}

2.1. Brand anthropomorphism in light of power

People readily and easily attribute and perceive human features in non-human entities, a phenomenon known as anthropomorphism (Epley, Waytz, \& Cacioppo, 2007). Therefore, managers often imbue brands with humanlike characteristics, motivations, and behaviors (either visually, textually, and/or rhetorically) to enable consumers to perceive the brand as an intentional agent that is capable of interacting with them (Fournier \& Alvarez, 2012). This high degree of sociality leads consumers to establish relationships that resemble those they establish with actual people (Fournier, 1998; MacInnis \& Folkes, 2017). 
As such, using anthropomorphized brands may facilitate purchase decisions based on consumers' desire to bond with a social entity (Fournier, 1998; Puzakova \& Kwak, 2017). If establishing social relationships with inanimate objects can help reduce feelings of loneliness, it can also help people feel in control over their environment (what MacInnis and Folkes [2017] labelled an "effectance motivation"). From this perspective, brands are used not to satisfy social needs through their perceived warmness, but to satisfy a need for control through their perceived ability to help consumers accomplish tasks and obtain desired outcomes (Fournier \& Alvarez, 2012; Khenfer et al., 2017). Thus, brand anthropomorphism may drive purchase based on the potential usefulness of the brand, thereby making consumerbrand relationships potentially hierarchical and endowing consumers with a position of power over the brand.

Power refers to people's beliefs regarding their capacity to control or influence the state of others according to their own will; a capacity conferred by the individual's ability to allocate or withhold valuable resources and administer punishments (Rucker, Galinsky, \& Dubois, 2012). People's subjective sense of power can be the result of their experience in occupying powerful positions, and thus, be expressed as a stable trait (Anderson \& Galinsky, 2006). Research has also extensively shown that people can feel powerful independently of their hierarchical position in their personal or professional life. Subjective sense of power can be activated when people are placed in a position where they are enabled to make decisions that affect others (Galinsky, Gruenfeld, \& Magee, 2003). Since an elevated sense of power relates to positive outcomes such as increased optimism (Anderson \& Galinsky, 2006) and perceived control (Fast et al., 2009), power can be conceived as a desirable state that, once activated, people seek to maintain.

In their review of the effect of power on consumer behavior, Rucker and colleagues (2012) report that an elevated sense of power fosters the expression of dominant acts whereas 
powerlessness fosters a disposition to consider others while engaging in decision-making. Unless brands have succeeded in becoming relationship partners, perhaps going as far as becoming friends and family (Fournier \& Alvarez, 2012), the inherent implication of buying products is to make use of them, which establishes a vertical relationship. As such, the brand preferences of people who perceived themselves low in power may be driven more by their unwillingness to make use of a fellow powerless social agent than by seeking companionship. In contrast, feelings of powerfulness encourage self-assertive and dominant behaviors (Rucker et al., 2012), which very essence lies in the presence of others (Weber, 1947/1978). This suggests that power fosters a disposition to seek out social targets, and thus anthropomorphized brands.

A budding marketing literature has begun to examine the relationship between power and brand anthropomorphism. For instance, Kim and McGill (2011) showed that consumers with high power were more willing to take risks when dealing with an anthropomorphized object (e.g., slot machine, illness) because they perceived a greater degree of control over it. In the same vein, researchers showed that constructs associated with power such as materialism (Kim \& Kramer, 2015) and financial status (Kim \& McGill, 2018) increased willingness to pay and product evaluations for products displaying anthropomorphic features related to submissiveness. Conversely, when abstract concepts such as time (May \& Monga, 2014) or the digestive system (Newton, Newton, \& Wong, 2017) were imbued with humanlike features, people who perceived themselves low (versus high) in power felt under the influence of the anthropomorphized entity and showed obedience toward it.

Thus, converging evidence shows that an elevated sense of power leads to a preference for anthropomorphized brands because power fosters feelings of social dominance and increases consumers' willingness to use such brands. Nevertheless, research makes no assumption regarding consumers' sense of competence. Perhaps this is because people tend to 
be optimistic about their ability to perform well when feelings of competence are not threatened (Bandura, 1994). Hence, when chronic and situational feelings of competence are high, we expected results to be in line with previous research:

H1: When chronic and situational feelings of competence are high (vs. low), an elevated sense of power increases the appeal of anthropomorphized brands.

$H 2$ : The increased appeal of anthropomorphized brands following an elevated sense of power in the context of high (vs. low) chronic and situational feelings of competence, is driven by increased feelings of social dominance.

Yet, not everyone feels constantly competent, nor can people escape situations that challenge feelings of competence. Then, would the relationship between power and brand anthropomorphism hold when perceived competence is low or under threat?

\subsection{The moderating role of perceived competence}

Empowering consumers involves providing them with sufficient knowledge and autonomy to allow them to exert control over a certain decision (Ozer \& Bandura, 1990). Evidence shows that consumers enjoy settings where they are enabled to demonstrate competence and creativity to the extent that such experiences do not leave them overwhelmed by a flow of instructions or too many product attributes (Thompson, Hamilton, \& Rust, 2005; Dahl \& Moreau, 2007). The viability of customer empowerment therefore relies on consumers perceiving their skills and abilities as adequate enough to act successfully, regardless of their actual competence.

Importantly, the relationship between empowerment and perceived competence is not necessarily causal. It is true that perceived competence can be conceived as a byproduct of power, insofar as power can produce an inflated perception of one's ability to reach desired outcomes on their own (Fast et al., 2009; Tost, Gino, \& Larrick, 2012). Nevertheless, people 
can feel competent or incompetent regardless of the power state they are in (Cho \& Fast, 2012; Fast \& Chen, 2009; Rucker et al., 2012). Suppose, for instance, Jack is told that he is in charge of building and monitoring his financial portfolio. Jack might feel inadequate in handling that sudden empowerment because of his inexperience in financial matters, the complexity of the information he is presented with, or because Jack is non-tech savvy and the task requires digital devices. Jack may possess the actual competence to perform the task but view himself as not competent enough to handle the requirements the task implies.

Past research suggests power holders whose competence has been threatened experience insecurity and diminished self-worth which they then compensate for by displaying denigration and aggressive tendencies toward their subordinates (Cho \& Fast, 2012; Fast \& Chen, 2009). Lacking competence is especially threatening to power holders in the context of social interactions with subordinates, where the power holder may feel at risk of being discredited. In a management context, Fast and colleagues (2014) showed that managers whose sense of competence was low were less willing to solicit input from employees and more negatively evaluated employees who spoke up.

In the context of brand anthropomorphism, brand relationships are not unidirectional but include consumers' perception of what they think brands think of them (MacInnis \& Folkes, 2017; Kim \& McGill, 2018). We expected that threats to feelings of competencethat is, situations heightening feelings of incompetence (e.g., negative feedback following a task)—would lead empowered consumers to feel negatively toward anthropomorphized brands. Specifically, we expected that they would avoid such brands, or when forced to engage with an anthropomorphized brand, feel resentment and dislike the product they represent. Resentment refers to the feeling of bitterness elicited by a situation perceived as unfair (Marticotte \& Arcand, 2017). As empowered consumers whose perceived competence has been threatened forcefully engage with an anthropomorphized brand, the negativity they 
experience because of it (e.g., insecurity) may overshadow and negate the positive experience of social dominance. Such consumers may feel resentful because they believe they were deprived from the enjoyable experience of social dominance that empowerment entails. Put differently, feelings of situational incompetence in presence of an anthropomorphized brand might dampen feelings of social dominance and heighten resentment toward a brand perceived as an obstacle preventing them from enjoying empowerment.

H3: When situational feelings of competence are low (vs. high), an elevated sense of power decreases the appeal of anthropomorphized brands.

H4: The decreased appeal of anthropomorphized brands following an elevated sense of power in the context of low ( $v s$. high) situational feelings of competence, is driven by increased feelings of resentment.

In contrast to situational incompetence, chronic sense of incompetence is fairly rare (e.g., severe case of depression; Bandura, 1994). We thus expected that when chronic sense of competence is below a certain threshold, an elevated sense of power would no longer lead individuals to seek out anthropomorphized brands to experience dominance, but would not lead to negativity toward them. Although self-doubts naturally set in following domainspecific perceptions of incompetence (e.g., failure to pass a test), most people endorse optimistic self-appraisals of capabilities, which allow them to go through life despite its impediments and difficulties (Bandura, 1994).

\section{Overview of studies}

Our hypotheses were tested across five studies. Studies 1 and 2 tested H1 by measuring participants' chronic perceived competence. We expected that the negative effect of power on preference for anthropomorphized brands would be triggered by threats to perceived competence. Accordingly, Studies 3, 4A, and 4B manipulated perceived 
competence and tested H3. Study 4A shed light on mechanisms and tested H2 and H4. Throughout our studies, we tested our hypotheses using real brands (Studies 1 and 2) and fictitious brands (Studies 3, 4A, and 4B). We considered sense of power as a chronic difference (Study 1) and a psychological state which we experimentally induced using memory tasks (Study 2) and marketing-relevant scenarios (Studies 3, 4A, and 4B). Pretests and manipulation checks designed to ascertain the effectiveness and orthogonality of our manipulations are provided in the Web Appendix.

\section{Study 1}

The purpose of Study 1 was to provide initial support for our hypothesis H1 that an elevated sense of power drives preference for anthropomorphized brands when chronic perceived competence is high but not low. This study consisted of two measured factors (sense of power and perceived competence).

\subsection{Procedure}

Participants were 103 American residents (37.9\% female, $M_{\mathrm{age}}=33.8, S D_{\mathrm{age}}=11.3$ ) who completed a study online (provider: Prolific). They were invited to participate in two unrelated studies. The "first study" was portrayed as focusing on consumer-brand relationships and contained our dependent variable. The "second study" was portrayed as a questionnaire investigating people's perception of themselves. Here, participants completed the sense of power scale (Anderson \& Galinsky, 2006) and the general self-efficacy scale (GSE) alongside filler questions (e.g., material value scale). The GSE scale measures “one's belief in one's overall competence to effect requisite performances across a wide variety of achievement situations" (Chen, Stanley, \& Eden, 2001, p. 63). Existing research highlights a slight difference between perceived competence and self-efficacy based on the notion that the 
former includes considerations of personal importance of the task (Rodgers et al., 2014). However, the fact that the GSE scale measures competence as stable trait makes that divergence inconsequential.

\subsection{Independent variables}

Perceived competence. Participants completed the 8-item GSE scale on a 7-point scale (1=disagree strongly, $7=$ agree strongly; $\alpha=.95, M=5.15, S D=1.10$ ). Scores were averaged. Example items include "When facing difficult tasks, I am certain that I will accomplish them," and "I am confident that I can perform effectively on many different tasks" (See Web Appendix).

Sense of power. Participants completed the 8-item power scale on a 7-point scale (1=disagree strongly, $7=$ agree strongly; $\alpha=.92, M=4.64, S D=1.08$ ). Scores were averaged. All items started with "In my relationships with others." Example items include "I can get people to listen to what I say" and "My wishes do not carry much weight (reversed)" (See Web Appendix).

\subsection{Dependent variable}

Participants were asked to choose which brands they preferred in each of five pairs of anthropomorphized versus neutral brands. Participants were told to choose as if they had to buy the product right now (snacks, breakfast cereal, canned vegetables, pancake mix, and house cleaners; see Appendix). A pretest $(N=168)$ found that for each of the five pairs of brands, there were as few differences as possible in terms of brand recognition, brand liking, frequency of buying, and sign of status (see Web Appendix). Further testing revealed that the anthropomorphized brands were successfully perceived as such (see Web Appendix). Five additional pairs of brands that did not differ with respect to anthropomorphism were included 
as fillers. The ten pairs of brands were presented in random order, as was the display order of the anthropomorphized versus neutral brand.

\subsection{Results}

We first tested for multicollinearity because of the expected correlation between power and GSE $(r=.61, p<.001)$. The variance inflation factors were equal to 1.91 , which is far below the critical threshold level of 10 (Hair et al., 2014), thus suggesting no multicollinearity concerns. Next, we conducted a repeated measures logistic regression analysis. Regressing preference for anthropomorphized brands on mean-centered power, mean-centered GSE, and their interaction revealed a marginally significant power $\times$ GSE interaction $(b=.11, S E=.06$, $Z=3.19, p=.074, \operatorname{Exp}(B)=1.12$ ) (along with no main effect of power, $b=.14, S E=.11, Z=1.72$, $p=.190, \operatorname{Exp}(B)=1.16$, or GSE, $b=-.06, S E=.10, Z=.30, p=.585, \operatorname{Exp}(B)=.945)$. To decompose further this interaction, we ran a floodlight analysis based on the Johnson-Neyman (JN) technique to identify regions of GSE in which the effect of power on preference for anthropomorphized brands was significant (Spiller et al., 2013). Supporting H1, we found that the effect of power on preference for anthropomorphized brands was significant $(p \leq .05)$ among participants whose GSE was higher than $6.05\left(b_{J N}=.25, S E=.13, \operatorname{Exp}(B)=1.28 ; 30 \%\right.$ of participants) and was non-significant below that threshold.

To conclude, we find evidence that chronic perceived competence is an important driver of the influence of power on preference for anthropomorphized brands. Specifically, Study 1 demonstrates that the probability of choosing an anthropomorphized (versus neutral) brand increases as consumers' sense of power grows concomitantly with their sense of competence.

\section{Study 2}


Study 1 measured sense of power as an enduring, stable difference and thus could not conclusively speak to the effect of engaging individuals in ad hoc power relations. Study 2 addressed this limitation and tested $\mathrm{H} 1$ by manipulating sense of power (high $v s$. low $v s$. neutral) and measuring chronic perceived competence.

\subsection{Procedure}

Participants were 260 American residents (41.5\% female, $M_{\mathrm{age}}=32.3$ years, $S D_{\text {age }}=11.9$ ) who completed a study online (provider: Prolific). Participants were invited to participate in two unrelated studies. The "first" study was portrayed as a recall task designed to investigate people's daily routine and served as our manipulation of sense of power. The "second" study was portrayed as focusing on consumer-brand relationships and served as our dependent variable. Finally, participants completed the GSE scale used in Study 1 to measure perceived competence.

\subsection{Independent variables}

Perceived competence. Participants completed the 8-item GSE scale used in Study 1 $(\alpha=.95, M=5.18, S D=1.15)$.

Sense of power. Participants were assigned to one of three conditions. In the highpower condition, participants thought of two occasions in their daily life or weekly routine when they feel powerful. We specified that "by power, we mean a situation in which you control the ability of another person or persons to get something they want, or are in a position to evaluate those individuals." In the low-power condition, participants thought of ten such occasions. We modeled these two conditions after ease-of-retrieval manipulations (Schwarz et al., 1991) and designed them to minimize differences in the content of the manipulation while altering people's sense of power. Our hypothesis was that people would 
feel less powerful after they tried to think of ten occasions when they are in a powerful position than after trying to think of two. Moreover, we included a neutral condition to test that powerfulness, and not powerlessness, was the driving force of our effect. Participants in the neutral condition were asked to think of two routine activities that they typically do on an average day. Pretesting revealed that participants in the high-power condition reported higher feelings of power than both those in the low-power condition $(p=.016)$ and the neutral condition $(p=.056)$. We found no difference between these last two $(p=.628)$. The absence of a significant difference between the neutral and low-power conditions is not surprising given that lacking power tends to be a more common psychological state than feeling powerful in life (Schaerer et al. 2018).

\subsection{Dependent variable}

Participants completed the dependent variable used in Study 1.

\subsection{Results}

We conducted a repeated measures logistic regression analysis. Regressing preference for anthropomorphized brands on the three power conditions (dummy coded with the highpower condition serving as baseline), mean-centered GSE, and the two interaction terms (high-power $v s$. low-power $\times$ GSE, and high-power $v$. neutral $\times$ GSE) revealed a significant high-power $v s$. low-power $\times$ GSE interaction, $b=-.21, S E=.11, Z=3.89, p=.048, \operatorname{Exp}(B)=.811$, but a nonsignificant high-power $v s$. neutral $\times$ GSE interaction, $b=-.12, S E=.11, Z=1.12$, $p=.289, \operatorname{Exp}(B)=.892$ (along with no main effect of high-power $v s$. low-power, $b=-.14$, $S E=.14, Z=.96, p=.328, \operatorname{Exp}(B)=.872$, high-power $v s$. neutral, $b=-.18, S E=.13, Z=1.99, p=.159$, $\operatorname{Exp}(B)=.836$, or GSE, $b=-.08, S E=.04, Z=2.82, p=.093, \operatorname{Exp}(B)=.928)$. Supporting H1, further analyses based on the JN technique revealed that the effect of high-power vs. low-power 
mind-set on preference for anthropomorphized brands was significant $(p \leq .05)$ among participants whose GSE was higher than $6.34\left(b_{\mathrm{JN}}=-.39, S E=.20 ; \operatorname{Exp}(B)=.679,15 \%\right.$ of participants; fig. 1) but not below that threshold. Therefore, participants with a high chronic perceived competence (above 6.34) expressed a preference for anthropomorphized brands when they were placed in a high (vs. low)-power situation.

Moreover, Figure 1 suggests that the responses of participants in the neutral condition were in between those of participants in the two power conditions, yet closer to the responses of participants in the low-power condition. While we found that the effect of high-power $v s$. neutral mind-set was marginally significant when GSE reached 6.34 ( $b=-.31, S E=.19, Z=2.75$, $p=.097, \operatorname{Exp}(B)=.732$ ), further analyses failed to reveal significant differences between lowpower and neutral mind-sets at any value of GSE. This is consistent with the results of the pretest of sense of power whereby participants in the neutral condition provided responses closer to those in the low-power condition than those in the high-power condition. Thus, the results of Study 2 suggest, as expected, that our effect was driven by feelings of powerfulness and not powerlessness. Furthermore, Study 2 suggests that an elevated sense of power can foster people's willingness to show dominance even if the boost in power is contextually disconnected from the purchasing decision.

\section{INSERT_FIGURE_1_ABOUT_HERE}

\section{Study 3}

Study 3 tested $\mathrm{H} 1$ and $\mathrm{H} 3$ by manipulating perceived competence. Moreover, this study aimed to test the robustness of our results to the inclusion of the perceived amiability of the preferred brand as a control variable. In Studies 1 and 2, we used brands ostensibly projecting amiability through smiles and overall positive expressions (see Appendix). One 
could therefore argue that we found our effect because the relationship between power and preference for anthropomorphized brands was distorted by the appeal of friendly brands. Study 3 ruled out this alternative explanation and used a 2 (sense of power: high $v s$. low) $\times 2$ (perceived competence: high vs. low) between-subjects design.

\subsection{Procedure}

Participants were 212 British residents $\left(70.5 \%\right.$ female, $M_{\text {age }}=39.3$ years, $S D_{\text {age }}=10.8$ ) who completed a study online (provider: Prolific). We used the consumption-relevant context of car rentals under the pretense of investigating people's reaction to renting a car in unfamiliar situations. Participants were asked to imagine that they wanted to spend a few days away in France. They further imagined that, as they were flying to their destination, they were thinking of renting a car to visit the surroundings. Participants were then informed that the renting procedure at the airport was done through a self-service machine. Our manipulations and measurements were portrayed as steps of the car renting procedure. The first step was a driving test designed to assess people's ability to drive in France (as foreigners) and served as our manipulation of perceived competence. The second step consisted of the renting procedure and served as our manipulation of sense of power. The third step consisted of a choice between two travel apps as a token of our appreciation and served as our dependent variable.

\subsection{Independent variables}

Perceived competence. Participants were asked to complete a driving test composed of ten multiple-choice questions based on real driving situations. Each webpage presented a photograph followed by a question about the lawful way to behave (see Web Appendix). Upon completion of the test, participants were reminded that the ten questions were based on 
a real driving test designed by the French driving and transport authority. They were then randomly assigned their scores via the software. Five categories of scores were possible: "Poor", "Fair", “Average”, "Good”, and "Excellent” and participants saw that their scores either fell in the range of "Poor" (low-perceived-competence condition) or "Excellent" (highperceived-competence condition). All participants subsequently received explanations about the meaning of their score regarding their ability to drive safely in France (see Web Appendix). Testing confirmed the credibility of the feedback following the test (see Web Appendix). A manipulation check revealed that our manipulation influenced perceived competence in the expected direction $(p<.001)$ without influencing feelings of powerfulness $(n s)$.

Sense of power. Participants in the high-power condition (random assignment) were introduced to a fictitious car rental company (Procar) with the following slogan "Your (temporary) car, your rules." They further read that "At Procar, you're in charge. You decide all there is to decide about the car. You decide about the model. You decide about the color. You decide where and when you want the car delivered to you. We comply with all your wishes." Participants were then asked a series of questions about their preferences to match this statement. In the low-power condition, participants read the slogan "Your (temporary) car, our rules" and that "At Procar, we assign you a car. The model displayed in the following screen will be attributed to you. By accepting the car, you agree to comply with our policy." All low-power participants were then given a series of statements about the designated car in terms of model, color, and delivery. Daily rates would be the same for all models across conditions (see Web Appendix). A manipulation check revealed that our manipulation influenced feelings of powerfulness in the expected direction $(p<.001)$ without influencing perceived competence $(n s)$. 


\subsection{Dependent variable}

Next, participants were told that, as a token of our appreciation, they could choose one of two travel apps. The apps were identical except for their logo. One logo was anthropomorphized while the other was not (see Appendix). Presentation order (left vs. right) was randomized. A pretest $(N=55)$ found no differences between logos in terms of familiarity $(|t(41)|=.46, p=.645)$ and liking $(|t(47)|=.91, p=.366)$. Furthermore, participants indicated to what extent they felt each logo looked like a person, had its own personality and seemed almost as if it had intentions on a 7-point scale ( $1=$ Not at all, $7=\mathrm{A}$ lot; $\left.\alpha_{\mathrm{anthro}}=.74, \alpha_{\text {neutral }}=.65\right)$. The anthropomorphized logo was perceived as more human-like $(M=4.60, S D=1.27)$ than the neutral logo $\left(M=2.53, S D=1.18,|t(46)|=10.11, p^{<.001)}\right.$.

\subsection{Control variable}

Finally, to measure perceived amiability, participants were asked to what extent they perceived the app they chose as a friend, a playmate, a companion, and a comrade on a 7point scale ( $1=$ Not at all, $7=\mathrm{A}$ lot; $\alpha=.91)$. Neither experimental factors, nor their interaction, had a significant effect on the perceived amiability of the chosen app ( $p s>.36)$. The following results account for the covariate but remained very similar without it (see Web Appendix).

\subsection{Results}

We conducted a logistic regression analysis to test the effects of power (low power=.5 , high power $=.5$ ), perceived competence (low competence $=-.5$, high competence $=.5$ ), their interaction, and the perceived amiability of the chosen app (i.e., the covariate) on preference for the anthropomorphized brand. The power $\times$ perceived competence interaction was significant, $b=1.45, S E=.57, Z=2.54, p=.011, \operatorname{Exp}(B)=4.26$ (along with no main effect of power, $b=.06, S E=.29, Z=.23, p=.822, \operatorname{Exp}(B)=1.07$ or perceived competence, $b=-.19$, 
$S E=.29, Z=-.70, p=.484, \operatorname{Exp}(B)=.82$; fig. 2). Importantly, spotlight analyses (Spiller et al. 2013) aligned with our predictions. Supporting H1, when feelings of perceived competence were high, high (vs. low)-power participants preferred the anthropomorphized logo over the neutral logo, $b=.79, S E=.41, Z=1.93, p=.054, \operatorname{Exp}(B)=2.20\left(M_{\text {High power }}=55.8 \% v s . M_{\text {Low }}\right.$ power $=38.5 \%$ ). Supporting H3, when feelings of perceived competence were threatened, high (vs. low)-power participants (marginally) preferred the neutral logo over the anthropomorphized $\log , b=-.66, S E=.40, Z=-1.66, p=.098, \operatorname{Exp}(B)=.52\left(M_{\text {High power }}=44.4 \%\right.$ vs. $M_{\text {Low power }}=61.1 \%$ ). Although the covariate (i.e., amiability) had a significant effect on brand preference $(b=.28, S E=.10, Z=2.83, p=.005, \operatorname{Exp}(B)=1.33)$, the fact that our effect persisted when accounting for it suggests that participants did not simply chose the anthropomorphized logo because it was perceived as amiable. A moderated mediation analysis revealed that perceived amiability did not mediate our effects (i.e., confidence intervals included zero; Hayes, 2018, model 8). Finally, controlling for driving experience and gender did not change the results.

\section{INSERT_FIGURE_2_ABOUT_HERE}

\section{Study $4 \mathrm{~A}$}

Study 4A had four goals. First, it tested H1 and H3 in the context of financial services. Second, it manipulated perceived competence based on actual performance whereas Study 3 relied on randomized feedback. Third, it forced consumers' engagement with a brand (anthropomorphized or neutral) during the empowerment experience and used brand evaluation rather than choice as the dependent variable. Previously, empowered participants whose sense of competence was altered had the choice of avoiding brands with anthropomorphic features (by not choosing it). Fourth, Study 4A examined mechanism and tested $\mathrm{H} 2$ and $\mathrm{H} 4$. We theorized that when empowered individuals feel competent, their 
preference for anthropomorphized brands are driven by a desire to engage in social relationships that facilitate the expression of dominant acts $(\mathrm{H} 2)$. But when empowered individuals feel incompetent, we expected feelings of resentment to overcome feelings of dominance and lead to the rejection of anthropomorphized brands (H4). Study 4 used a 2 (sense of power: high $v s$. low) $\times 2$ (perceived competence: high $v s$. low) $\times 2$ (brand anthropomorphism: anthropomorphized brand $v s$. neutral brand) between-subjects design.

\subsection{Procedure}

Participants were 444 British residents ( $49.3 \%$ female, $M_{\mathrm{age}}=36.5$ years, $S D_{\mathrm{age}}=9.7$ ) who completed a study online (provider: Prolific). While Studies 1 to 3 relied on a rule of thumb whereby we allocated at least 50 participants per cell, the sample size of Study 4A was based on an a priori power analysis to detect an effect size of $f=0.16$ (estimated from previous studies) with a power of 0.80 and $\alpha=0.05$ (Cohen, 1988) and given non-random assignment within the competence conditions. We used the consumption-relevant context of financial services. Participants were instructed to imagine that they received a rather significant amount of money relative to their household income (e.g., work bonus, unexpected cash gift) and that they wanted to invest the money. They then imagined that while looking for investment information online, they found P\&M Capital (a fictitious investment firm). Participants read that many banks and financial institutions try to get a sense of their customers' level of familiarity with financial matters as a preliminary step toward investment. In that vein, they were asked to complete a 16-question financial literacy test. This served as our manipulation of perceived competence. Next, participants imagined they continued exploring P\&M Capital's website and stumbled on their service offering. This second phase served as both our manipulation of sense of power and our manipulation of brand anthropomorphism. Finally, 
participants completed the dependent variable and mechanism variables followed by manipulation-check questions.

\subsection{Independent variables}

Perceived competence. Participants were asked to complete a financial literacy test adapted from Fernandes, Lynch, and Netemeyer (2014) which assesses people's ability to understand and engage in both short-term financial management and long-term financial planning (see Web Appendix). Following each question, participants could see the correct answer and were provided their score upon completion. They were further told that the same test had been completed by a large representative sample of consumers and a graph displayed the score distribution (see Web Appendix). Participants who scored lower than 60 percent (9 or less correct answers), were told that they had scored lower than most people (lowperceived-competence condition, $n=168)$. Participants who scored higher than 60 percent (10 or more correct answers, high-perceived-competence condition, $n=276$ ) were told they had scored higher than most people. The 60 -percent threshold was based on a pretest $(N=100)$. All participants subsequently read an explanatory statement about the meaning of their score (see Web Appendix). A manipulation check revealed that our manipulation influenced perceived competence in the expected direction $(p<.001)$ without influencing feelings of powerfulness $(n s)$.

Sense of power. Participants were randomly assigned to one of two power conditions. In the high-power condition, participants were introduced to the fictitious investment firm with the following slogan "Take charge of your money" and description "Experience more power, more control. P\&M Capital introduces you to an online platform designed to let you build your own customized investment portfolio, to monitor your performances in real time, and to make adjustments as you see fit. You can access the online platform 24/7, anywhere in 
the world." In the low-power condition, participants read the following slogan "The investment firm in charge of your money" and description "Experience more sincerity, more authenticity. Call on our team of professionals to get started with your investment portfolio, to monitor your performances, and to make adjustments as they see fit. You can call our team $24 / 7$ or find them in our local branches." Hence, low-power participants were told that they needed to go through the investment firm to manage their money, whereas high-power participants were empowered to do it themselves. In both conditions, the description of the service offering was extended across four webpages (see Web Appendix). A manipulation check revealed that our manipulation influenced feelings of powerfulness in the expected direction $(p<.001)$ without influencing perceived competence $(n s)$.

Brand anthropomorphism. As participants learned about P\&M Capital's service offering, they were randomly exposed to one of two logos (see Appendix). The logo was present on the four webpages describing the service offering. While the service offering description was identical across conditions, the anthropomorphized-brand condition included speech bubbles to emphasize the anthropomorphic features of the $\log$ (

\subsection{Dependent and mediating variables}

Next, participants rated P\&M Capital's service offering on three items using a 7-point semantic differential scale (1=Bad, Unappealing, Negative; 7=Good, Favorable, Positive, $\alpha=.95$ ). Participants then rated how dominant they felt (i.e., "dominant/strong," $r=.82, p<.001$ ) and how resentful they felt (i.e., "resentful/bitter," $r=.93, p<.001)$ while looking over P\&M Capital's service offerings on a 7-point scale ( $1=$ Not at all, 7=Very).

\subsection{Control variable}


We measured perceived amiability of the brand (i.e., "I see P\&M Capital as friendly/ sympathetic/ welcoming" $1=$ Not at all, $7=$ Completely, $\alpha=.90$ ) as a covariate as in Study 3 . A $2 \times 2 \times 2$ ANOVA on perceived amiability revealed nonsignificant effects. The following results account for the covariate but remained similar without it (see Web Appendix).

\subsection{Results}

Service offering ratings. An ANCOVA predicting participants' ratings of the service offering yielded the predicted three-way interaction, $F(1,435)=5.58, p=.019, \eta^{2}{ }^{2}=.013$ (along with a main effect of perceived amiability, $F(1,435)=165.27, p<.001, \eta^{2}{ }_{p}=.275$, but no main effect of power, $F(1,435)=.04, p=.847, \eta^{2} \mathrm{p}=.000$, perceived competence, $F(1,435)=.14$, $p=.714, \eta^{2}{ }_{\mathrm{p}}=.000$, or brand anthropomorphism, $\left.F(1,435)=.23, p=.630, \eta^{2}=.001\right)$. Simple effects revealed that the interaction unfolded as expected (fig. 3). First, supporting H1, when the brand was anthropomorphized and perceived competence was high, high (vs. low)-power participants rated the service offering more positively $\left(M_{\text {High power }}=5.65, S D=.91 \mathrm{vs} . M_{\text {Low }}\right.$ power=5.14, $\left.S D=1.30, F(1,435)=5.58, p=.019, \eta^{2}{ }_{\mathrm{p}}=.013\right)$. Second, supporting H3, when the brand was anthropomorphized and perceived competence was low, high (vs. low)-power participants rated the service offering less positively $\left(M_{\text {High power }}=5.04, S D=1.61 \mathrm{vs} . M_{\text {Low }}\right.$ power $\left.=5.65, S D=.99, F(1,435)=3.76, p=.053, \eta^{2}{ }_{\mathrm{p}}=.009\right)$.

Put differently, when perceived competence was high, high-power participants exposed to an anthropomorphized brand rated the service offering more positively than highpower participants exposed to a neutral brand $\left(M_{\text {Anthro }}=5.65 \mathrm{vs} . M_{\text {Neutral }}=5.06, S D=1.48, F(1\right.$, $\left.435)=3.67, p=.056, \eta^{2}=.008\right)$. This difference was reversed when perceived competence was low. High-power participants exposed to an anthropomorphized brand rated the service offering more negatively than high-power participants exposed to a neutral brand 
$\left(M_{\text {Anthro }}=5.04\right.$ vs. $\left.M_{\text {Neutral }}=5.47, S D=1.02, F(1,435)=3.23, p=.073, \eta^{2}=.007\right)$. Effects remained when controlling for education and participants' score at the financial literacy test.

\section{INSERT_FIGURE_3_ABOUT_HERE}

Mechanism. We then ran a moderated mediation model following Hayes (2018, model 12). We predicted that feelings of dominance (resentment) drove the effect of power on the appeal (rejection) of anthropomorphized brands, but not neutral brands, when feelings of competence were bolstered (threatened). In separate regressions predicting the two mechanism variables from power, perceived competence, brand anthropomorphism, and all their interactions, we found that the three-way interaction was marginally significant on feelings of dominance $(b=-.82, S E=.45,|t(435)|=1.68, p=.093, d=.16)$ and significant on feelings of resentment $(b=-1.32, S E=.50,|t(432)|=2.63, p=.009, d=.25)$.

Spotlight analyses (Spiller et al., 2013) revealed that high (vs. low)-power participants reported greater feelings of dominance given an anthropomorphized brand and under highperceived competence $(b=.60, S E=.21,|t(435)|=2.88, p=.004, d=.28)$ but not under lowperceived competence $(b=.35, S E=.27,|t(435)|=1.32, p=.19, d=.13)$. Given a neutral brand, we found no difference between power conditions under high-perceived competence $(b=.31$, $S E=.21,|t(435)|=1.50, p=.136, d=.14)$ and a negative effect of power under low-perceived competence $(b=-.76, S E=.27,|t(435)|=2.79, p=.006, d=.27)$. Further spotlight analyses revealed that high ( $v s$. low)-power participants reported greater feelings of resentment given an anthropomorphized brand and under low-perceived competence $(b=.87, S E=.28$, $|t(432)|=3.13, p=.002, d=.30)$ but not under high-perceived competence $(b=.03, S E=.22$, $|t(432)|=.13, p=.90, d=.01)$. Given a neutral brand, we found no difference between power 
conditions under high-perceived competence $(b=.10, S E=.22,|t(432)|=.46, p=.647, d=.04)$ or under low-perceived competence $(b=-.38, S E=.28,|t(432)|=1.34, p=.182, d=.13)$.

Next, in a single regression predicting participants' ratings of the service offering with perceived amiability, the two mediators, the experimental variables, and all the interactions, feelings of dominance $(b=.25, S E=.04,|t(430)|=6.69, p<.001, d=.64)$ and feelings of resentment $(b=-.14, S E=.04,|t(430)|=3.91, p<.001, d=.40)$ were significant predictors. Moreover, using a bootstrapping procedure with 5,000 samples, we found that given an anthropomorphized brand and under high-perceived competence, power predicted ratings through feeling of dominance ( $C I_{95}$ : .040 to .271), thus supporting H2. We also found that given an anthropomorphized brand and under low-perceived competence, power predicted ratings through feelings of resentment ( $C_{95}:-.289$ to -.016), thus supporting H4. No other indirect effect emerged (see Web Appendix). Thus, feelings of dominance (resentment) mediated the effect of power on the appeal (rejection) of anthropomorphized brands, but not neutral brands, when feelings of competence were bolstered (threatened).

\section{Study 4B}

Because Study 4A forced participants to engage with a brand (anthropomorphized or neutral), it did not include a measure of brand preference. Hence, to provide more direct evidence for our assumption that lower (higher) service offering ratings suggested brand rejection (endorsement), we ran a follow-up study in which we measured brand preferences. Moreover, this follow-up study aimed to account for confounding factors stemming from the context of financial services used in Study 4A. One could argue that the perceived difficulty of taking financial decisions and the desire to seek advice could have confounded with our independent variables and led participants to assess more favorably the anthropomorphized option because of its perceived inherent ability to help. Study 4B ruled out these alternative 
explanations and used a 2 (sense of power: high $v s$. low) $\times 2$ (perceived competence: high $v s$. low) between-subjects design.

\subsection{Procedure}

Participants were 252 American residents (51.6\% female, $M_{\text {age }}=36.5$ years, $S D_{\text {age }}=9.2$ ) who completed a study online (provider: Prolific). Sample size was determined using the rules previously provided. Study 4B replicated the manipulations of perceived competence and sense of power used in Study 4A before measuring brand preference between two financial instruments whose resemblance was betrayed by their brand names and logos (anthropomorphized or neutral).

\subsection{Independent variables}

Perceived competence. Participants completed the manipulation used in Study 4A with two notable differences. First, we modified the threshold we used to allocate participants to conditions because of the large discrepancy in cell size we observed in Study 4A. Participants who provided 10 or less correct answers out of 14 were allocated to the low-perceivedcompetence condition $(n=114)$ whereas those who provided 11 or more correct answers out of 14 were allocated to the high-perceived-competence condition $(n=138)$. Second, the feedback participants received following the test varied depending on conditions. High ( $v s$. low)perceived-competence participants read that the average score obtained by a large sample of consumers to the same test was $60 \%$ (vs. $75 \%$ ). In doing so, we aimed to highlight their performance or lack thereof. Manipulation checks provided results consistent with Study 4A (see Web Appendix). 
Sense of power. Participants completed the manipulation used in Study 4A. Manipulation checks revealed that the manipulation had the expected effect (see Web Appendix).

\subsection{Dependent variable}

Participants were asked to imagine that after further exploring the P\&M Capital website, they were looking over a selection of investment products, which led them to develop an interest for Exchanged Traded Funds (ETFs). After reading information on ETFs, participants imagined that they decided to invest their sudden infusion of cash through one of the two ETFs based on US offerings provided by P\&M Capital. The two EFTs were virtually identical (e.g., return; see Web Appendix) except for their name and logo (see Appendix). Preference for one or the other served as our dependent variable. We employed three items, captured on 11-point scales: "Which ETF would you prefer to buy between Cape Expertise and The Expert?" "Which ETF would you choose between Cape Expertise and The Expert?" and "For which ETF would you pay the management fees between Cape Expertise and The Expert? (+5=Definitely prefer Cape Expertise, $+5=$ Definitely prefer The Expert; $\alpha=.92)$. The scales were subsequently converted to be anchored by (-5) and (+5) with higher scores representing preference for the anthropomorphized option. Presentation order (left or right) was randomized across participants.

\subsection{Control variables}

Finally, we measured the perceived difficulty of making a financial decision on a 7point scale (1=Extremely difficult, 7=Extremely easy). Neither experimental factors, nor their interaction, had a significant effect on perceived difficulty ( $p s>.13)$. We also measured participants' desire to seek advice: "To what extent do you think you require the help of a professional advisor when it comes to investment products?" and "To what extent do you 
think you need someone to give you advice when it comes to investment products?" on 7point scales ( $1=$ Not at all, $7=\mathrm{A}$ lot; $r=.82, p<.001)$. Although perceived competence had a significant effect on desire to seek advice $(p<.001)$, the effects of power and the competence $\times$ power interaction were not significant ( $p s>46)$. We measured perceived amiability of the chosen ETF using the items in Study 4A; a 2×2 ANOVA revealed nonsignificant effects. The following results account for the three covariates but remained similar without them (see Web Appendix).

\subsection{Results}

An ANCOVA predicting preference for the anthropomorphized option yielded the predicted two-way interaction, $F(1,245)=12.11, p=.001, \eta^{2} \mathrm{p}=.047$ (along with no main effects of perceived amiability, $F(1,245)=.33, p<.568, \eta^{2}{ }^{2}=.001$, perceived difficulty, $F(1,245)=.00$, $p=.987, \eta^{2}{ }_{p}=.000$, desire for advice, $F(1,245)=1.22, p=.267, \eta^{2}{ }_{p}=.005$, perceived competence, $F(1,245)=.00, p=.949, \eta^{2}{ }_{\mathrm{p}}=.000$, or power, $\left.F(1,245)=.22, p=.716404, \eta^{2}=.001\right)$. Simple effects revealed that the interaction unfolded as expected (fig. 4). First, supporting H1, when feelings of perceived competence were high, high (vs. low)-power participants preferred the anthropomorphized option to the neutral option $\left(M_{\text {High power }}=.99, S D=1.87\right.$ vs. $M_{\text {Low power }}=-.02$, $\left.S D=1.56, F(1,245)=8.64, p=.004, \eta^{2} \mathrm{p}=.034\right)$. Second, supporting H3, when feelings of perceived competence were low, high ( $v s$. low)-power participants preferred the neutral option to the anthropomorphized option $\left(M_{\text {High power }}=.23, S D=2.06 v s . M_{\text {Low power }}=.99\right.$, $\left.S D=2.27, F(1,245)=4.17, p=.042, \eta^{2}{ }_{\mathrm{p}}=.017\right)$. A moderated mediation analysis revealed that none of the covariates mediated our effects (i.e., confidence intervals included zero, Hayes 2018, model 8). The fact that our effects persisted when accounting for the covariates brings 
further support to our theorizing. Effects remained when controlling for education and participants' score at the financial literacy test. ${ }^{1}$

\section{INSERT_FIGURE_4_ABOUT_HERE}

\section{General discussion}

Five studies supported our hypotheses. In Studies 1 and 2, we measured perceived competence as a stable trait under the assumption that individuals tend to form positive selfappraisals of capabilities, and found that an elevated sense of power drives preference for anthropomorphized brands when chronic sense of competence is high but not low. In Studies 3, 4A, and 4B, we found that when participants' perceived competence was threatened ( $v s$. bolstered), consumer empowerment lowered ( $v s$. increased) the appeal of anthropomorphized brands. Study 4A further examined mechanism and revealed that empowering consumers while their feelings of competence were threatened no longer heightens feelings of dominance but led to feelings of resentment. Overall, these results provide evidence for the existence of divergent effects of power on preference for anthropomorphized brands depending on consumer perceived competence.

\footnotetext{
${ }^{1}$ Four weeks after data collection, we contacted the participants and asked them to fill the GSE scale from Studies 1 and $2(M=5.30, S D=1.14) ; 203$ of them participated (dropout rate was identical between conditions). Regressing preference for the anthropomorphized option on power, mean-centered GSE, their interaction, and the three covariates revealed a marginally significant power $\times$ GSE interaction $(b=.44, S E=.25, t(193)=1.77$, $p=.077$; without covariates: $p=.043$ ). Further analyses based on the JN technique revealed that the effect of high (vs. low)-power was significant $(p \leq .05)$ among participants whose GSE was higher than $5.96\left(b_{J N}=.64 S E=.32\right.$, $t(193)=1.97 ; 34 \%$ of participants) and was non-significant below that threshold. This is consistent with the results of Studies 1 and 2 .
} 


\subsection{Theoretical contributions}

This research adds to the budding literature on power and brand anthropomorphism. First, our work highlights that the relationship between power and brand anthropomorphism holds only when consumers feel competent. Consistent with others (Bandura, 1994; Fast et al., 2014), Studies 1 and 2 found that feelings of competence were relatively high in the absence of threat (i.e., significantly higher than mid-scale, $p s<.001$ ). While this can explain the results of prior works (e.g., Kim \& McGill, 2011), we showed that the appeal of anthropomorphized brands based on the experience of power disappeared when perceived competence was not high. What's more, our findings suggest that empowering customers when they must deal with competency threats can lead to an avoidance tendency or negative evaluations of product bearing anthropomorphic features.

Second, this research highlights the role of brand engagement in empowerment contexts crippled with threats to perceived competence. Incompetence in high-power situations can heighten insecurity and trigger mechanisms of ego defensiveness (Cho \& Fast, 2012; Fast \& Chen, 2009; Fast et al., 2014). However, past research has not shown when incompetent power holders denigrate or merely avoid subordinates. Put all together, our studies suggest that when low-competence empowered consumers have a choice, they choose to avoid the unpleasantness of exposing their incompetence by preferring neutral brands. However, when forced to engage with an anthropomorphized brand, this unpleasantness seems to translate into resentment, which in turn negatively affects product evaluation.

Third, this research brings insight on the motivational factors that drive brand anthropomorphism. Despite predictions that consumers would prefer anthropomorphized brands under competency threat as a way of helping them regain control over their environment (MacInnis \& Folkes, 2017), we found the opposite depending on one's level of 
power. This does not mean that we discard desire for competence as a potential driver of brand anthropomorphism. Brands may be seen as enabling the self by providing consumers with a sense of competence (Park, Eisingerich \& Park, 2013), especially if the brand projects competence and reliability (Khenfer et al., 2017). The current research highlights the interplay between power and perceived competence on brand relationships.

\subsection{Managerial implications}

Our findings suggest that managers should be mindful when empowering customers. We found that providing consumers with the power to make decisions that affects others or the company did not necessarily bear the expected effects. While we focused on brand anthropomorphism, we found that perceived competence played a crucial role on the behavioral consequences of power. Therefore, programs designed to empower customers should occur concurrently with initiatives to boost their sense of competence, for instance, through positive feedback and encouragements.

Moreover, although managers often attribute anthropomorphic features to their brands, this practice is not always relevant and may even backfire. Consumers are often told that they have power regardless of whether or not they actually have any kind of control over the purchasing process or the various aspects of their lives. For instance, Burger King famously

declares "Have it your way." Relying as such on cues of empowerment in contexts of brand anthropomorphism - Burger King' mascot: “the King”- appears effective, or at the very least, not detrimental, as long as consumer perceived competence is not threatened. If perceived competence is threatened, activating a high-power mind-set may drive consumers away. As such, non-tech savvy consumers may be put off by the perspective of "having it their way" through a self-service kiosk under the eyes of the well-known mascot. 


\subsection{Limitations and future research}

Although our findings were replicated across several studies, some questions remain. While Study 2 shows that our effect is driven by feelings of powerfulness, the results of Study 3 lead us to wonder whether feelings of powerlessness can also influence consumer preference for anthropomorphized brands. The effect of our power manipulation in the lowperceived-competence condition seems to rely on feelings of powerlessness (see fig. 3). We found that when sense of power was lowered, low ( $v s$. high)-perceived-competent participants preferred the anthropomorphized brand more $(b=-.92, S E=.41, Z=-2.27, p=.024 \operatorname{Exp}(B)=.40$; $M_{\text {Low } \text { competence }}=61.1 \%, v s . M_{\text {High }}$ competence $\left.=38.5 \%\right)$. We found no significant difference between the preferences of low-power/low-competence participants and those of high-power/high competence participants. Nevertheless, this result does not discard our claim that power decreases the appeal of anthropomorphized brands when feelings of perceived competence are threatened. It suggests that, in such circumstances, taking power away from consumers leads them to seek social support even among inanimate objects. This is consistent with research suggesting that being lower in the hierarchy makes individuals more dependent on others for valuable resources (Rucker et al. 2012).

Moreover, one could argue that the anthropomorphized brands used throughout our studies were docile, unthreatening. A brand displaying a strong and authoritarian character as its logo (e.g., Captain Morgan) might repel individuals who feel powerful. Despite high levels of perceived competence, they might see a challenger to their power and prefer to avoid it as a way of maintaining their desire to dominate. On top of brand personality, the personal importance of the task for which feelings of competence have been altered may also play a critical moderating role in how our effects unfold. To the extent that people put their sense of competence into perspective when they take on personally important tasks (Rodgers et al., 2014), it is possible that the unappealing effect of anthropomorphized brands weakens 
(strengthens) if the purchasing context has little (strong) relevance for them. These remaining questions constitute as many directions for further research.

Finally, one could note that some of our results were only marginally significant with small effect sizes. While sample size plays a crucial role in the statistical power of a test and may have been a factor in the present case (Cohen, 1988), it may be that our estimates are correct but the size of our effect is small in the real world. The reality is that estimates of effect sizes in past literature tend to be inflated and that most true effect sizes tend to be small (Meyvis \& Osselaer, 2018). Nevertheless, it does not mean that our effects are irrelevant. In a marketing environment where competition grows ever more aggressive, every bit helps.

\section{References}

Aggarwal, P., \& McGill, A. L. (2012). When brands seem human, do humans act like brands? Automatic behavioral priming effects of brand anthropomorphism. Journal of Consumer Research, 39(2), 307-323.

Anderson, C., \& Galinsky, A. D. (2006). Power, optimism, and risk- taking. European Journal of Social Psychology, 36(4), 511-536.

Bandura, A. (1994). Self-efficacy. In V. S. Ramachaudran (Ed.), Encyclopedia of human behavior (Vol. 4, pp. 71-81). New York: Academic Press. (Reprinted in H. Friedman [Ed.], Encyclopedia of mental health. San Diego: Academic Press, 1998).

Bloomberg (2017). How more Americans are getting a perfect credit score. https://www.bloomberg.com/news/features/2017-08-14/obsessives-have-cracked-the-perfectfico-credit-score-of-850 (Accessed 12 April 2020).

Chen, G., Gully, S. M., \& Eden, D. (2001). Validation of a new general self-efficacy scale. Organizational Research Methods, 4(1), 62-83. 
Cho, Y., \& Fast, N. J. (2012). Power, defensive denigration, and the assuaging effect of gratitude expression. Journal of Experimental Social Psychology, 48(3), 778-782.

Cohen, J. (1988). Statistical Power Analysis for the Behavioral Sciences. Hillsdale: Lawrence Erlbaum Associates.

Dahl, D. W., \& Moreau, C. P. (2007). Thinking inside the box: Why consumers enjoy constrained creative experiences. Journal of Marketing Research, 44(3), 357-369.

Epley, N., Waytz, A., \& Cacioppo, J. T. (2007). On seeing human: a three-factor theory of anthropomorphism. Psychological Review, 114(4), 864.

Fast, N. J., Burris, E. R., \& Bartel, C. A. (2014). Managing to stay in the dark: Managerial self-efficacy, ego defensiveness, and the aversion to employee voice. Academy of Management Journal, 57(4), 1013-1034.

Fast, N. J., \& Chen, S. (2009). When the boss feels inadequate: Power, incompetence, and aggression. Psychological Science, 20(11), 1406-1413.

Fast, N. J., Gruenfeld, D. H., Sivanathan, N., \& Galinsky, A. D. (2009). Illusory control: A generative force behind power's far-reaching effects. Psychological Science, 20(4), 502-508.

Fernandes, D., Lynch Jr, J. G., \& Netemeyer, R. G. (2014). Financial literacy, financial education, and downstream financial behaviors. Management Science, 60(8), 18611883.

Fournier, S. (1998). Consumers and their brands: Developing relationship theory in consumer research. Journal of Consumer Research, 24(4), 343-373.

Fournier, S., \& Alvarez, C. (2012). Brands as relationship partners: Warmth, competence, and in-between. Journal of Consumer Psychology, 22(2), 177-185.

Galinsky, A. D., Gruenfeld, D. H., \& Magee, J. C. (2003). From power to action. Journal of Personality and Social Psychology, 85(3), 453-466. 
Hair, J. F., Black, W. C., Babin, B. J., \& Anderson, R. E. (2014). Multivariate Data Analysis. ( $7^{\text {th }}$ ed). Harlow: Pearson.

Hayes, A. F. (2018). Introduction to mediation, moderation, and conditional process analysis: A regression-based approach. (2 $2^{\text {nd }}$ ed.). New York: Guilford Publications.

Khenfer, J., Laurin, K., Tafani, E., Roux, E., \& Kay, A. C. (2017). Interventionist external agents make specific advice less demotivating. Journal of Experimental Social Psychology, 73, 189-196.

Kim, H. C., \& Kramer, T. (2015). Do materialists prefer the "brand-as-servant"? The interactive effect of anthropomorphized brand roles and materialism on consumer responses. Journal of Consumer Research, 42(2), 284-299.

Kim, H. Y., \& McGill, A. L. (2018). Minions for the Rich? Financial Status Changes How Consumers See Products with Anthropomorphic Features. Journal of Consumer Research. 45(2), 429-450.

Kim, S., \& McGill, A. L. (2011). Gaming with Mr. Slot or gaming the slot machine? Power, anthropomorphism, and risk perception. Journal of Consumer Research, 38(1), 94107.

MacInnis, D. J., \& Folkes, V. S. (2017). Humanizing brands: When brands seem to be like me, part of me, and in a relationship with me. Journal of Consumer Psychology, 27(3), 355-374.

Maeng, A., \& Aggarwal, P. (2018). Facing Dominance: Anthropomorphism and the Effect of Product Face Ratio on Consumer Preference. Journal of Consumer Research, 44(5), 1104-1122.

Marticotte, F., \& Arcand, M. (2017). Schadenfreude, attitude and the purchase intentions of a counterfeit luxury brand. Journal of Business Research, 77, 175-183. 
May, F., \& Monga, A. (2014). When time has a will of its own, the powerless don't have the will to wait: Anthropomorphism of time can decrease patience. Journal of Consumer Research, 40(5), 924-942.

Meyvis, T., \& Van Osselaer, S. M. (2018). Increasing the power of your study by increasing the effect size. Journal of Consumer Research, 44(5), 1157-1173.

Newton, F. J., Newton, J. D., \& Wong, J. (2017). This is your stomach speaking: Anthropomorphized health messages reduce portion size preferences among the powerless. Journal of Business Research, 75, 229-239.

Ozer, E. M., \& Bandura, A. (1990). Mechanisms governing empowerment effects: a self-efficacy analysis. Journal of Personality and Social Psychology, 58(3), 472-486.

Park, C. W., Eisingerich, A. B., \& Park, J. W. (2013). Attachment-aversion (AA) model of customer-brand relationships. Journal of Consumer Psychology, 23(2), 229-248.

Pew Research Center (2014). Older Adults and Technology Use. https://www.pewresearch.org/internet/2014/04/03/older-adults-and-technology-use/ (Accessed 12 April 2020).

Puzakova, M., \& Kwak, H. (2017). Should Anthropomorphized Brands Engage Customers? The Impact of Social Crowding on Brand Preferences. Journal of Marketing, 81(6), 99-115.

Rodgers, W. M., Markland, D., Selzler, A. M., Murray, T. C., \& Wilson, P. M. (2014). Distinguishing perceived competence and self-efficacy: An example from exercise. Research Quarterly for Exercise and Sport, 85(4), 527-539.

Rucker, D. D., Galinsky, A. D., \& Dubois, D. (2012). Power and consumer behavior: How power shapes who and what consumers value. Journal of Consumer Psychology, 22(3), 352-368. 
Schaerer, M., du Plessis, C., Yap, A. J., \& Thau, S. (2018). Low power individuals in social power research: A quantitative review, theoretical framework, and empirical test. Organizational Behavior and Human Decision Processes, 149, 73-96.

Schwarz, N., Bless, H., Strack, F., Klumpp, G., Rittenauer-Schatka, H., \& Simons, A. (1991). Ease of retrieval as information: another look at the availability heuristic. Journal of Personality and Social Psychology, 61(2), 195-202.

Spiller, S. A., Fitzsimons, G. J., Lynch Jr, J. G., \& McClelland, G. H. (2013). Spotlights, floodlights, and the magic number zero: Simple effects tests in moderated regression. Journal of Marketing Research, 50(2), 277-288.

Thompson, D. V., Hamilton, R. W., \& Rust, R. T. (2005). Feature fatigue: When product capabilities become too much of a good thing. Journal of Marketing Research, 42(4), 431-442.

Tost, L. P., Gino, F., \& Larrick, R. P. (2012). Power, competitiveness, and advice taking: Why the powerful don't listen. Organizational Behavior and Human Decision Processes, 117(1), 53-65.

Weber, M. (1947/1978), Economy and Society: An outline of interpretive sociology, Berkeley: University of California Press. 
Fig. 1. Effect of sense of power on preference for anthropomorphized brands for all values of perceived competence (Study 2).

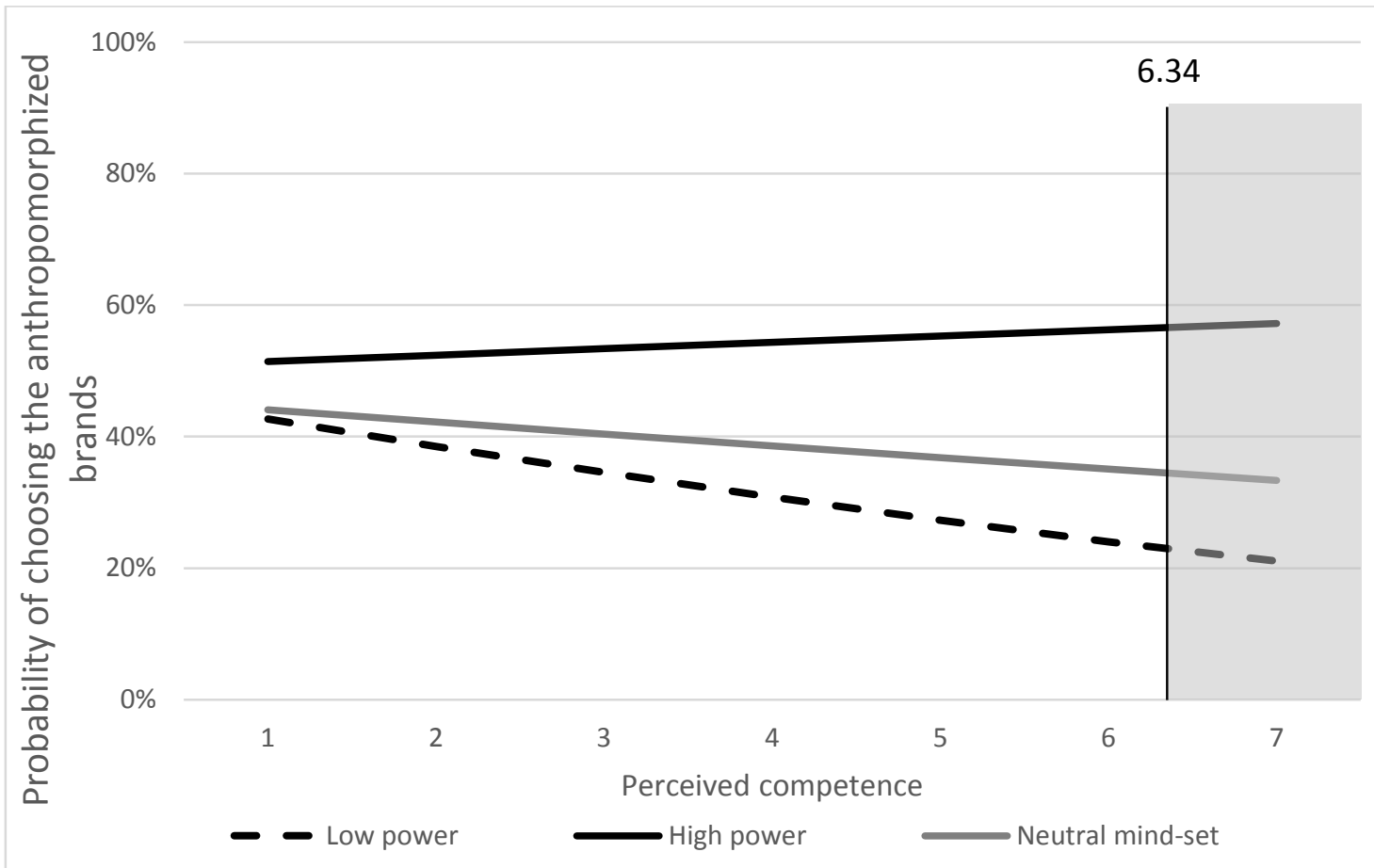

Region of significance of the effect of high vs. low-power mind-sets on preference for anthropomorphized brands 
Fig. 2. Effect of sense of power on preference for the anthropomorphized option depending on levels of perceived competence (Study 3).

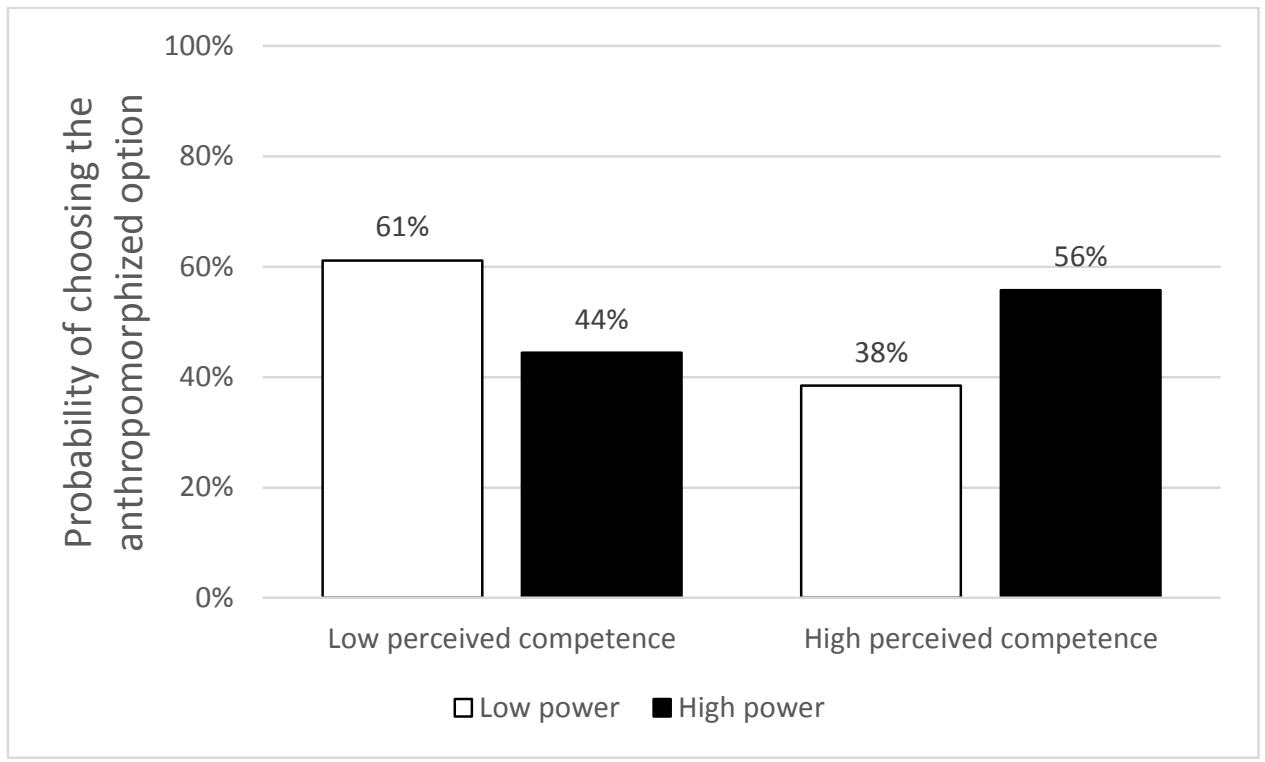


Fig. 3. Effect of sense of power on service offering ratings depending on levels of perceived competence and brand anthropomorphism (Study 4A).

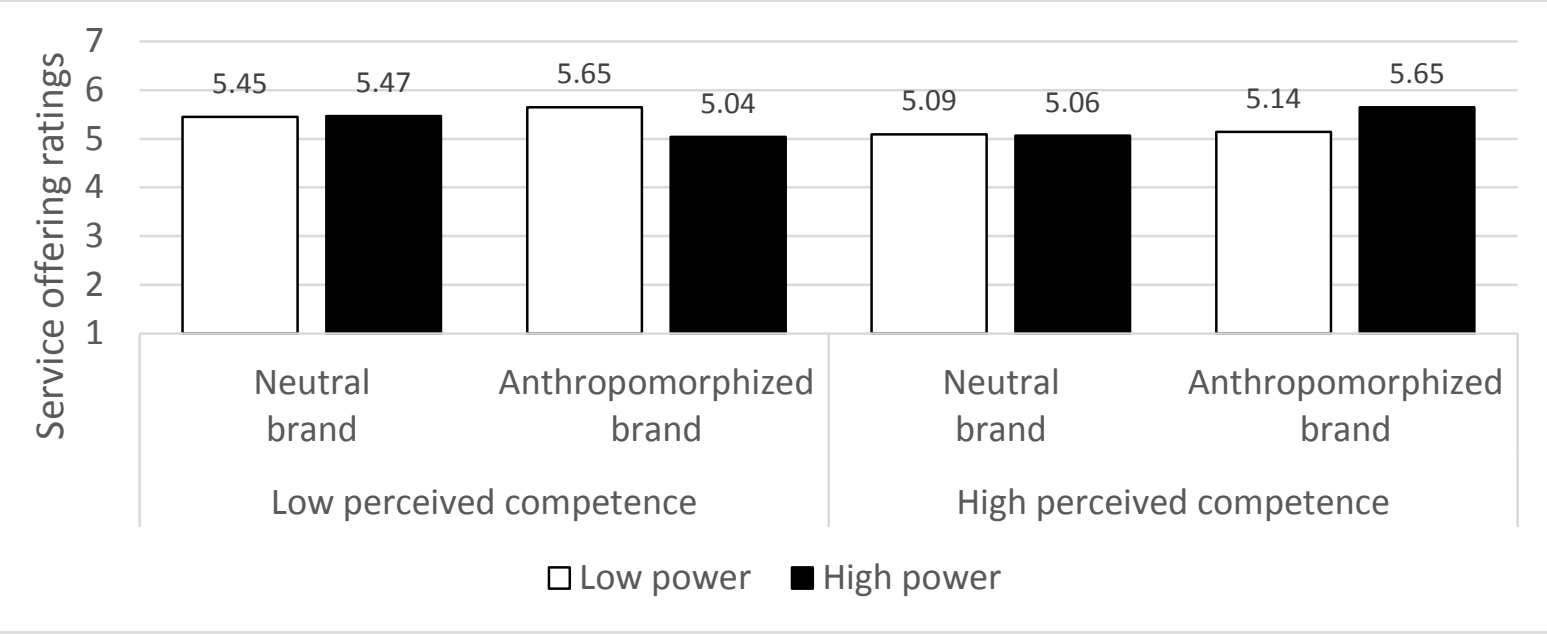


Fig. 4. Effect of sense of power on preference for the anthropomorphized option depending on levels of perceived competence (Study 4B).

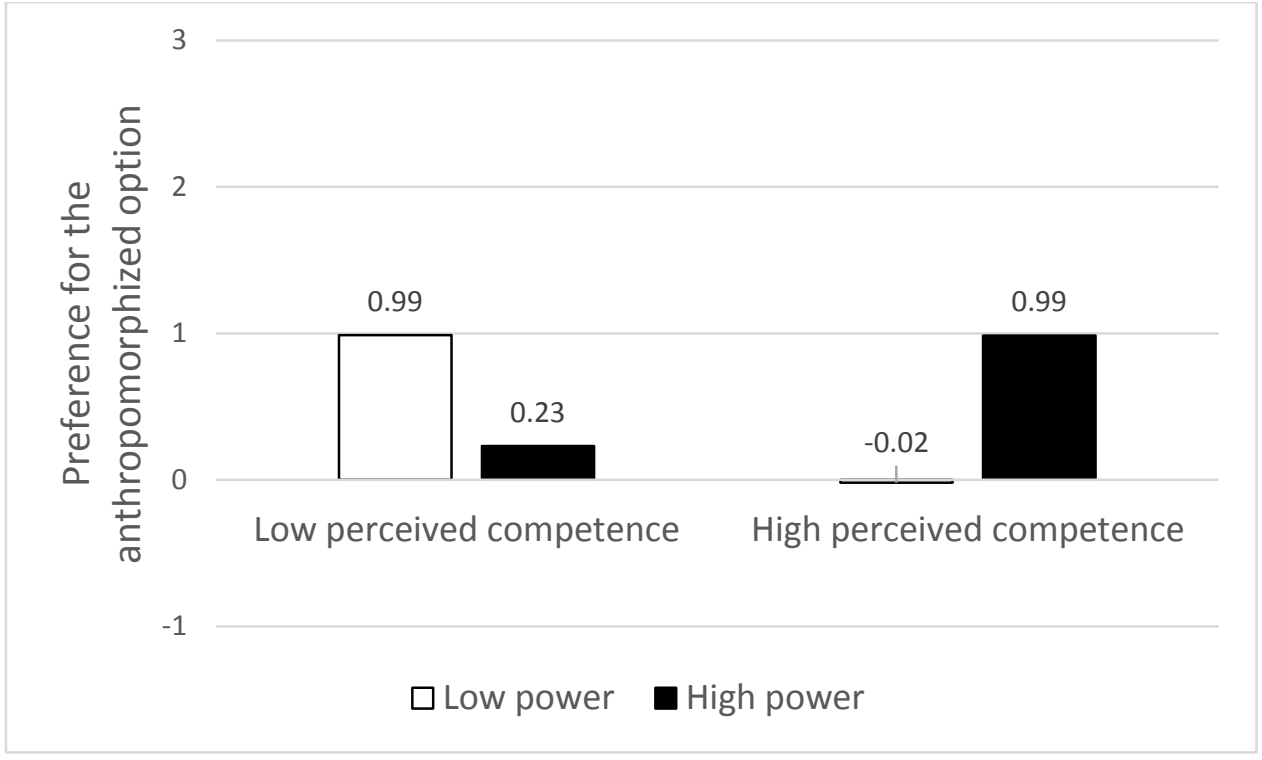


Appendix. Pairs of anthropomorphized vs neutral brands used in Studies 1 to 4 .

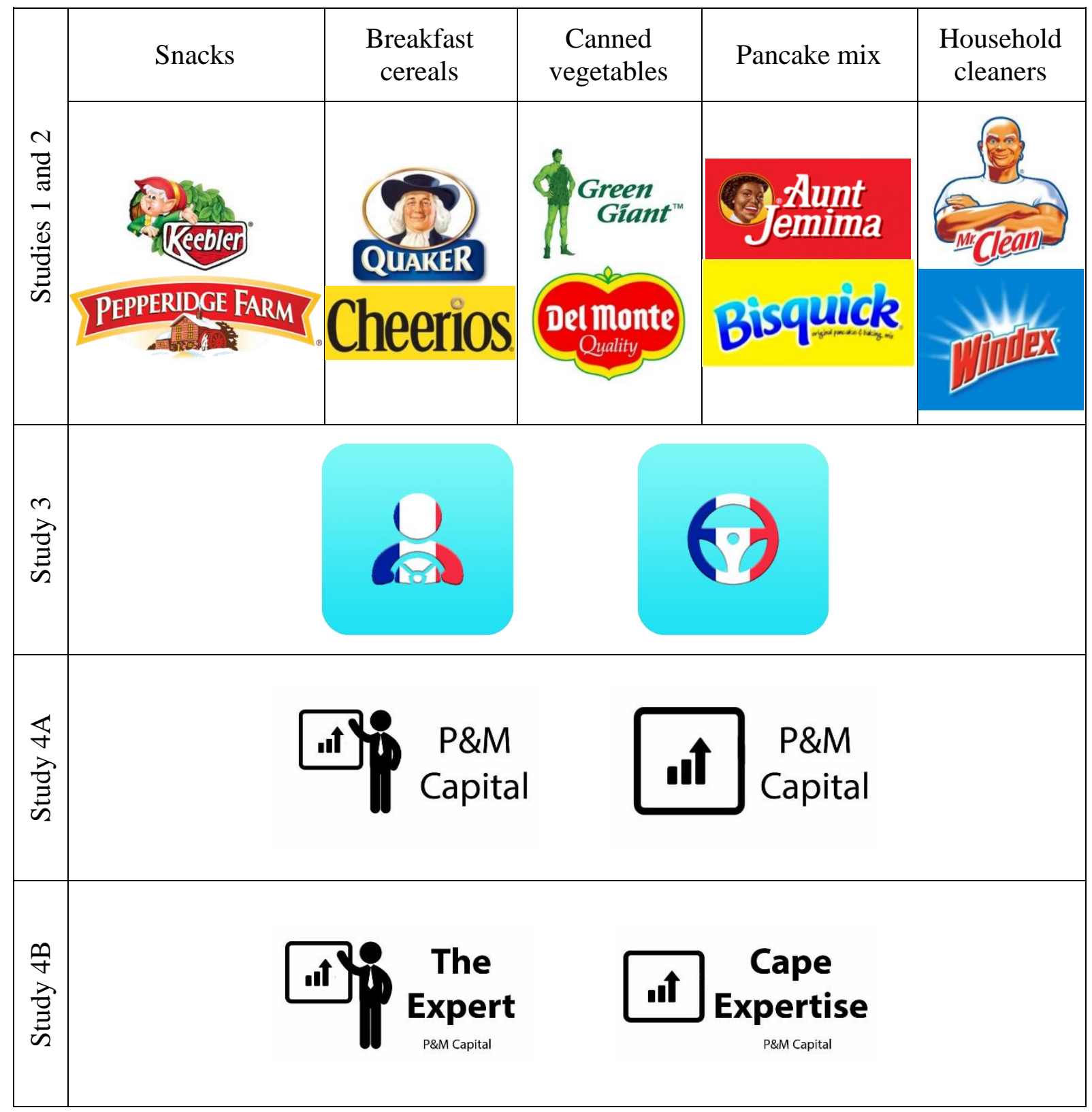


Click here to access/download e-component JBR-D-18-03789-Web Appendix-RR Final.docx 
Jamel Khenfer is an assistant professor of Marketing at Zayed University, College of Business, Abu Dhabi (United Arab Emirates). He holds a Ph.D. in Marketing from AixMarseille University (France). His research has been published in Journal of Experimental Social Psychology and others. He also develops mobile applications under the developer name "J Khenfer" on Google Play.

Steven Shepherd is an assistant professor of Marketing at Oklahoma State University, Spears School of Business (USA). He holds a Ph.D. in Social Psychology from the University of Waterloo (Canada). His research has been published in Journal of Consumer Research and others.

Olivier Trendel is a professor of Marketing at Grenoble Ecole de Management, Grenoble (France). He holds a Ph.D. in Marketing from the University of Grenoble (France). His research has been published in Journal of Marketing Research and others. 